The Geneva Papers on Risk and Insurance, 20 (No. 77, October 1995), 430-438

\title{
The Paradox of Welfare and Insurance
}

\author{
by C.J.M. Schuyt*
}

\section{Summary}

Insurances provide solidarity, and the premium is the price for avoiding risks. But with the passing of time the insured have increasingly come to look on the premium as a payment that gives rights. People took less care and personal responsibility made way for the shifting of responsibility onto society as a whole. Higher claims led to higher premiums, thus reinforcing this behaviour. Changes are necessary in the way the system of insuring is organised, but these changes need to be in harmony with the sense of responsibility prevailing in a society.

\section{Introduction}

Luck and chance play a remarkably important role in modern society. Games of chance and lotteries are flourishing. Each month there are at least three gaming shows on television, with millions of viewers experiencing whether the contestant will manage to put the right key in the right lock of a pretty expensive car. Many people permit themselves a slight chance of great happiness through a lottery ticket. At the same time, the same people have insured themselves against a minor risk of a major accident. The paths of luck and fate appear to run parallel via the laws of probability and the law of large numbers, but anyone pondering this for a moment will see how striking is the asymmetry of luck and fate. A missed opportunity of a positive outcome is shrugged off with a smile: it was only a game, the stake wasn't high, better luck next time. Reactions are different to the slight chance that something negative will occur in life: well, I've paid my premiums, so now I'm entitled to compensation. The «well» and the «so» in particular are striking. In the case of luck an awareness of chance prevails, in the case of fate, however, an awareness of rights

\footnotetext{
* The author is Professor of Sociology at the University of Amsterdam.
} 
predominates. In the welfare state the government is expected to concern itself with the fate of many, in spite of the fact that these many have themselves given fate a perfectly accepted place in their lives. It seems as though people do consider themselves responsible for positive actions and events, but shrink from responsibility when things end on a negative note.

In this article I would like to discuss the paradox of responsibility, welfare and insurance. I call it a paradox because the State first spread and insured the risks of a modern society in so far as possible through a large number of collective schemes, only to find after a number of decades that the claims being made on all these schemes have grown to such an extent that their limits are in sight. A return to personal responsibility is increasingly being seen as a necessity. The crux of an insurance - irrespective of whether it is a group or private insurance, compulsory or voluntary - is, however, that the negative effects of a person's own or someone else's actions and the fateful consequences of uncertain events are removed from the shoulders of the individual. Successful systems of insurance increasingly hid personal responsibility from sight. The recalling of personal responsibility therefore often goes little further than an exhortation to take out insurance against certain risks oneself and to pay the premiums for these insurances oneself. From compulsory to voluntary, from government or quasi-government to private, and from an automatic giro slip from the employer to an automatic giro slip from the employee: will this be the step from welfare state to insurance state?

\section{Personal responsibility}

The immediate reason for the call for a return to personal responsibility is the overburdening of the system. The size of collective taxes, the national debt and the total cost of the welfare state are causing concern. Together they are preventing a strong recovery in employment in the Netherlands, creating a vicious circle in which these costs remain excessively high. I shall let the widely known complaint about the Dutch welfare state rest here in order to point out a number of well-documented developments in the use of social benefits.

To be precise, after 1972, the third decade of the post-war welfare state, actual claims on virtually all social benefits in the Netherlands rose spectacularly, whereas the economic base for this expansion was lacking from as early as 1973 . The criteria for access to social benefits were either stretched by law - I have in mind here in particular the Disablement Benefits Act (WAO) - or were in practice privately interpreted more and more liberally. The interests of many parties involved often coincided, and I am not just thinking here of those of employer and employee in the fall of major industries - the textile industry in Twente, shipbuilding in Rotterdam, as a result of which the individual misfortune of dismissal was offloaded onto the collective funds of the disablement benefits scheme. Another example is the privately insured patient who increasingly requested and obtained from the treating specialist medical grounds for a hospital confinement: after all, both parties had an interest in this diagnosis. Thus hospital confinements rose spectacularly while the number of children has continued to fall since 1970 . Where the interests of the insured and the providers run parallel, it is difficult to dam the flood. 
Have there been too few checks? Should private insurers have been much stricter in all these matters? Saying «no» in the collective sector proved to be very difficult - and, of course, it is. In the face-to-face meeting between an insured person who has suffered a negative experience and a decision-maker who does not have to bear the financial consequences of his decisions himself it is easier to point out all the statutory possibilities for compensation or recovery than to explain why in this particular instance no benefit or compensation can be given after all. Medical examiners know a thing or two about this. The new measures in the field of social security and health insurances are based on the assumption that access, checks, management and administration by the social partners who have a vested interest in these measures are the chief reasons why the burden - of bearing each other's load - has become too hard to bear. But I venture to doubt whether the deeper causes have thus been traced and will be able to be removed.

For a lesser known fact is that in about the same period between 1975 and 1985 private insurance companies were also increasingly faced with higher frequencies of claims, more cases of individual fraud or attempts at fraud and general pressure on the system. Minor accidents in day-to-day traffic were transformed into major losses. Sunglasses proved to be a very popular object for theft and loss - even at holiday destinations where the sun does not shine so brightly. Later on, sunglasses proved to turn automatically into expensive watches, jewellery and other easily losable items.

Private insurance companies too found it difficult to say no, albeit for totally different reasons: the game was not worth the candle, the administrative costs and a thorough investigation of each incident weighed heavier in terms of time and money than automatic settlement, and here again the misfortune suffered by the individual could be offloaded onto society as a whole. The insured pays part of the collective bill himself, with the result that a vicious spiral started here as well: if I pay so much extra, I shall make sure I get my individual costs back.

In short, in addition to the intriguing relationship between the increase in petty, common crime and the collective shifting of responsibility, there are sufficient pointers for taking an in-depth look at the disappearance of individual responsibility in the public and private sectors. There appears to be a learning effect in progress: private citizens and insured first manage to secure certain allocated rights - in themselves no more than abstract claims for the event of something happening - then they start to count on these rights - the abstract claim becomes concrete - and later again they start to calculate - reality is distorted to make a claim as high as possible. The calculating citizen emerges automatically from the system with a delay of about ten to fifteen years. As a result of their organisation, operation and control mechanisms, systems appear to generate effects that bring about exactly the opposite of what the systems were first set up for: systems of collective solidarity appear after some time to elicit and encourage maximisation of use by the individual, which undermines this solidarity and so accentuates the call for a return of individual responsibility. Before suggesting some solutions to this paradox of insurance and welfare, I would first like to take a more in-depth look at the social and cultural changes that have resulted in this behaviour. 


\section{Modern lack of concern and bureaucracy}

In spite of much heard calls for renewed responsibility in politics and society, the bearing or taking of responsibility has only seldom been analysed as a social phenomenon. By now there are many who feel that on the one hand personal responsibility has been taken away, whilst on the other it is being advanced as a stiff remedy for the ailments of the modern welfare state. There's something not quite right here. If responsibility has been removed, has disappeared from sight, it is not going to be easy to recall at politicians' behest. In that case, there is more to the matter.

\subsection{The weakened tie between action and consequence.}

Responsibility always supposes a close tie between human action and the consequences of that action, between performance and reward or between non-performance and penalty. The loss suffered must somehow be related to the human action, otherwise it is impossible for anyone to be held responsible for it. Now, this golden rule of responsibility and freedom has already been considerably stretched by modern liability law: in certain circumstances you can be deemed responsible for the consequences of actions that took place through no fault of your own and against your will. The losses suffered and the possibilities for recovering these losses nowadays weigh heavier before the courts than the demonstrable tie between voluntary action and its consequences. In other words, the direct link between personal action and the consequence of that action has already been substantially weakened in law. Administration of the law has become functional, that is to say it has started to pay more attention to social relationships and social consequences than to the elements of will and intent when acting. Increasingly, the deciding factor is not who does something and with what intent, but what was done and with what harmful consequences.

In liability law there is a very clear trend towards direct responsibility being lost from view. This applies in particular to the United States where claims are sometimes absurdly high (partly on account of the system of financing lawyers), but a similar trend can now be seen in the Netherlands as well.

\subsection{Extending causality chains}

Added to this there are other social factors, like the technique of the modern production process that has almost entirely eradicated any view of the chain between action and the consequence of that action. People no longer see what they are making, no longer know what they are eating or where it comes from, everything comes into the home readymade. Causality chains have been extended enormously: radioactive precipitation from Russia affects the food of reindeer in Lapland, which subsequently keeps the food inspection departments of Western Europe at work. They ought to reject the meat bought in bulk from the slaughterhouses, but it has already been sold on to small butchers who put it on our plates that same evening in the restaurant. The blood scandal in France has similar long, complicated chains of human action. Sometimes it is possible to point to clear responsibility, but generally a dense fog surrounds socially organised action. Individual fault makes little difference. 
What applies to technology applies equally well to the socio-technology of largescale, bureaucratic organisations. The division of tasks into smaller ones makes individual responsibility for that very small task less relevant, because it is less visible, but at the same time it renders responsibility for the overall result less accountable as well. In a bureaucracy - and I'm not just thinking of government bureaucracies - everyone works responsibly and no-one is responsible. The scale of our organisations has changed individual responsibility for the consequences of our own actions. Here again, individual fault is no longer of much relevance. From this point of view, the call for a return to personal responsibility could be interpreted more as a final convulsion of individuality in a world in which there is virtually no room left for individuality.

\subsection{Insurance against risks}

A third factor in the disappearance of the tie between action and the consequence of that action is the cost involved in paying for services and indemnifying losses. No-one can walk around in this world uninsured. We are already insured at the cradle for the grave. The need for total care is not specific to the welfare state. Only a handful of farmers still dare to accept the slings of fate, and even this is - rightly or wrongly - being made impossible where health risks are concerned. We all prefer to pay a small, calculable and regular premium than a large bill in one go, emanating from the chaos of possibilities of human action. On a small scale almost everyone prefers the makability and controllability of individual existence at a time when large-scale makability is being hotly disputed.

Thanks to the large-scale application of government benefits and private insurance it has been possible to remove as far as possible the negative effects of luck, fate and disaster. We feel the pain of modern life in our pockets as little as we feel the sun, the wind and the rain in modern shopping malls.

\subsection{Consequences for the modern attitude to life}

The so ingenious systems of welfare and insurance have, however, resulted in two features of the modern attitude to life which are opposite yet reinforce each other.

On the one hand, there is a general expectation that all misfortune will be compensated in some form or another, that no-one need bear the consequences of his own or someone else's action or suffer from unexpected natural forces entirely alone any more. The complaint of travellers on the wrecked Achille Lauro that the Dutch Government did not send an aircraft with help swiftly enough has strikingly enough replaced the understanding in private law that the organising companies are in the first instance liable for the loss. Where the Prime Minister attempted to dam the endless flood of disability claims with a strong hand and an appeal to personal responsibility, he was generous with promises in regard to the consequences of a different flood, the floods caused by the rivers. It is impossible to see any consistency in views in politics concerning responsibility or in the differences between human agency and natural occurrence. If nature is not entirely makable and controllable, then at least the financial consequences of its unmakability are for the government's account.

On the other hand, there is an attitude of unconcern and a certain degree of indifference to the operation and maintenance of this magnificent machinery of welfare and insu- 
rance. Just as in the relationship of luck and fate, I find here a similar asymmetry in the advantages and disadvantages of welfare and insurance. When things are going badly for me, the community looks after me. When things are going well for me, I don't need to worry about the system. Others do that.

I see no anomaly in the simultaneous occurrence of sweeping claims for support and an equally sweeping lack of concern and indifference. Both phenomena can be explained as the long-term learning effect of the increasing invisibility of the tie between action and its consequence, the disappearance from sight of individual responsibility.

The political choice to move the moment of insurance from the compulsory and collective level to the voluntary/individual appears to be in the spirit of the time, but no-one yet has provided an answer to the expectation of support that is highly likely to come from all those careless people who, hoping for the best or due to social need, have not taken out insurance. Are we in the future going to let people die in the streets or at the gates of our hospitals? If politicians continue to feed the expectations of citizens for compensation on the occasion of each major or minor disaster, then it seems to me wiser and more consistent for the state not to distance itself from the uninsurable risks and cases that with difficulty can insure themselves.

Modern lack of concern and indifference with regard to collective goods and services are both a response to the often anonymous forms of bureaucratic organisation that encourage indifference and to the «one good turn deserves another» attitude that has politics and the economy so much in its spell. Where everything is deemed makable, controllable and manipulable, the morality of those insured and those receiving welfare likewise becomes makable, although we would never have thought that of that morality. A morality that changes to suit time, place and opportunity seems strange, but is a home-grown product. Instead of a highly moralistic rejection of this phenomenon, I suggest a fundamental consideration of the working of welfare and insurance systems. Anyone who gets annoyed at the modern attitude to life with its twofold lack of concern - lack of concern for future misfortune, lack of concern for one's personal contribution to the welfare system - should realise that this attitude to life was able to develop exactly as a result of the success of welfare and insurance.

\section{Reorganisation of welfare and insurance}

If this analysis of the paradox of welfare and insurance holds any water, it can have repercussions for the reorganisation of the welfare state and the privatisation of insurances that once were collective. Some of the problems of lack of concern and exaggerated expectations of compensation, of 'free-rider' behaviour and manipulation, will continue to manifest themselves, even if everything is put into private hands. Claims will not disappear if suddenly an appeal is made to personal responsibility. Much depends on how the systems are organised. Allow me to give a few examples and put forward some suggestions.

\subsection{Personal responsibility}

More personal responsibility means placing crucial choices with individuals or private organisations. In addition to proper information it assumes, of course, an express awareness of the link between one's own action and bearing the consequences of one's own 
actions. I am pessimistic about the degree to which substantial portions of our population support this idea. Anyone who does not take out insurance or does not do so promptly, anyone who does not pay punctually, etc. will bear the negative effects of these actions. Are the system and those implementing the system willing to take this hard line and are the decision-makers prepared for this? Can those politically responsible suffer more and more desperate cases of those who cause their own downfall? If the answer to this is in the negative, less haste should be made in switching to privatisation, or insurance should again be made compulsory and sensible access mechanisms introduced - exactly the opposite of what is being advocated.

\subsection{Excess}

Greater use of an excess appears to be a splendid way of giving concrete shape to and a suitable symbolisation of personal responsibility. If the size of the excess remains bearable, it will indeed reinforce the tie between action and its consequence. Naturally, the size of the excess is a matter for debate. Can we expect people to skip a holiday because of the excess payable if they should be hospitalised? Can we expect children to be taken out of the pony club because the excess for medicines is being increased sharply? What relation does the excess bear to a general incomes policy? Largely embracing the first presupposes relinquishing the latter. I hope that politicians will remain consistent. Greater use of an excess will not only increase the awareness of cost among the insured but will also encourage greater care. The no-claims bonus in the case of motor-vehicle damage has a greater preventive effect than any government sanction whatsoever.

\subsection{Non-anonymous organisations}

The bureaucratic control of modern large-scale welfare and insurance programmes is undermining personal identification with a suprapersonal matter. The indifference with which the large social-insurance organisations treated their clients was mostly counter-productive: clients started to get as much out of them as they could. A comparison with the implementation of social security in Belgium, where locally known representatives play a crucial role at the implementation level, would certainly not be out of place here.

Bureaucratic indifference produces indifference in the recipients. Breaking through this negative spiral of behaviour will - due to competition and customer relations - be accomplished slightly easier in private than in government organisations, but on account of the law of large numbers, which is inherent in collective welfare and insurance, transferral of the administration of social insurances from the social partners who have a vested interest to former politicians taking an interest is no guarantee at all of improved efficiency or management. The same problems of implementation will emerge. Automation will reduce personal service. Intermediaries, who often play a key role in the non-escalating response to bureaucratic indifference, may disappear.

All these developments are in my view at variance with the suggestion that it is exactly small-scale personal service that is the best antidote to modern unconcern. Implementing organisations should therefore become smaller and clearer, instead of larger and more anonymous. If insurance organisations continue with large-scale makability and control, they will encourage and encounter the small-scale makability of their clients. 


\subsection{More checks}

More and stricter checks on access to and continuance in all welfare and insurance systems has proved necessary. The legitimacy of every system has suffered badly under the indulgence of the Dutch welfare state. The expectation that private implementing organisations will carry out stricter checks than government organisations is often expressed, but I see no reason as such for it. Naturally, it is possible to point to the discipline of the market and the need to make operating profits, but it is first and foremost a question of the culture of organisations. It is still a mystery why strict checks on access to disablement benefits were not introduced. Was it due to statutory provisions, to the implementers and decision-makers, or to the expectations and morality of the clients? Nothing prevents a government organisation from carrying out strict checks on access and on the condition of the insured.

On the issue of checks, the advantages of technology and automation could be combined with the advantages of small-scale, surveyable implementation. The human dimension could also provide for the rediscovery of the social and moral dimensions of welfare and insurance. From the point of view of legitimacy and combatting petty crime, there is a lot to be gained from a systematically constructed, well-thought-out system of checks. I suspect that private organisations will realise this sooner than the government. It's a good reason for switching to privatisation, but it remains strange to place the concern for public morality in private hands for this reason.

\subsection{The circle of insured}

From the above analysis it follows that the choice of scale of the circle of insured affects how the system operates. If the circle is placed at the highest and most anonymous level of an entire society, as happened with very many systems in the welfare state, then all the problems of anonymity, large scale, indifference, lack of concern, calculation and fraud will manifest themselves with telling effect. If the circle is placed at the lowest level of the private individual or an individual company, the advantages of spreading risk and the possibilities of covering risk will soon be cancelled out. At the lowest level other matters start to play a part, e.g. the strong and inadmissible branding of the carrier.

The optimum size of a system of welfare and insurance could well work out very close to the former, now so reviled pooling of risks according to branch of industry. The option of placing the organisation of insurance and welfare mainly with individual companies and individual persons, issuing from a sensed need for the restoration of personal responsibility, could have inexcusable consequences.

\section{Conclusion}

This brings me to my overall and perhaps paradoxical conclusion with regard to the call for a return to personal responsibility in the welfare state. In order to give personal responsibility another chance, the system of insurance will need to be modified not only at the level of the individual person or the individual company, but modifications should in particular be made to the organisation of the insurance systems and the way in which they operate, especially where excesses, anonymous implementation and checks are concerned. Individual responsibility is something that is very difficult to discover and preserve in a 
modern society where almost all risks have been removed. In order to save these last remnants of individuality and responsibility, insurance and welfare programmes will need to be evolved and implemented just above this personal level. Personal responsibility thrives best in a society tailored to human dimensions. I have no understanding of insurance but this point of view, prompted by common sense and sociological insight, appears to me to be entirely tenable and worth recommendation. 